$\mathbb{T}$ periodica polytechnica

Chemical Engineering $52 / 1(2008) 29,33$

doi: $10.3311 /$ pp.ch.2008-1.06 web: http://www.pp.bme.hu/ch

(c) Periodica Polytechnica 2008

RESEARCH ARTICLE

\section{Solvent extraction of Vanadium (IV) with di(2-ethylhexyl) phosphoric acid and tributyl phosphate}

\author{
Moussa Alibrahim / Habib Shlewit / Safaa Alike
}

Received 2005-10-19

\begin{abstract}
Vanadium pregnant solution recovered from the Syrian Petroleum coke by means of salt roasting was acidified by dilute sulfuric acid. Solvent extraction of tetravalent vanadium with a mixture of di(2-ethylhexyl) phosphoric acid (DEHPA) and Tributylphosphate (TBP) was carried out. Kinetic effects are involved in competitive extraction of other metals such as iron and aluminum.
\end{abstract}

\section{Keywords \\ extraction $\cdot$ vanadium $\cdot T B P+D E H P A$}

\section{Acknowledgement}

The authors would like to express their thanks to General Director of the Syrian Atomic Energy Commission Prof. I. Othman and to the Head of the Chemistry Department for their encouragement to carry out this work. The authors would like to extend their thanks to $\mathrm{Mr}$. A. Rezekallah for his valuable help to carry out this work.

\section{Moussa Alibrahim}

Atomic Energy Commission, Chemistry Department, P.O.Box 6091 Damascus, Syria

\section{Habib Shlewit}

Atomic Energy Commission, Chemistry Department, P.O.Box 6091 Damascus, Syria

e-mail: scientific@aec.org.sy

\section{Safaa Alike}

Atomic Energy Commission, Chemistry Department, P.O.Box 6091 Damascus, Syria

\section{Introduction}

Vanadium is commercially important as a constituent of several alloys and catalysts. Nowadays, Vanadium is mostly recovered as a co-product from secondary sources or from industrial waste streams such as titaniferrous magnetite, fly ash, spent catalysts and petroleum coke.

Toyabe et al. [1], Gupta et al. and Remya et al. [2,-4] they claim that solvent extraction is one of the techniques being increasingly used for the recovery of vanadium. A survey of literature Biswas et al. [5], Hirai et al. [6], Brunette el al. [7] and Zhang et al. [8] showed that organophosphorus acid derivatives such as di-2-ethylhexylphosphoric acid (DEHPA) are the most convenient extractants for tetravalent vanadium. Saji and Reddy [9] indicated that mono-2-ethylhexylester (EHEHPA) have been widely used for the extraction of vanadium (V) from both acidic chloride and sulfate solutions. Among the neutral organophosphorus extractants, tributylphosphate (TBP) have been used for the extraction of vanadium $(\mathrm{V})$ from hydrochloric acid solutions, Tedesco and De Rumi, [10]. Tetravalent vanadium can be extracted by acidic organophosphorus reagents, e.g. (DEHPA), an extractant used by ORNL Crouse et al. [11] and Ryon et al. [12]. R. C. Merritt [13] indicated that, solvent extraction of vanadium from sulfuric acid solutions is possible with an organic phase containing from 3 to 10 percent DEHPA and from 2 to 5 percent TBP in kerosene base, the actual content being varied depending upon the vanadium content of the feed solutions. Six stages were needed in the extraction circuit.

The purpose of this paper is to evaluate the conditions of a selective solvent extraction of vanadium (IV) recovered from the Syrian petroleum coke with a mixture of DEHPA and TBP in kerosene.

\section{Experimental}

2.1 Materials and methods

Tributyl phosphate (TBP) $99 \%$ purity and $\operatorname{Di}(2-$ ethylhexyl)phosphoric acid(DEHPA) 99\%, were supplied by Merck. Kerosene with a flash point of $76^{\circ} \mathrm{C}$ used as diluent supplied by Pemco Chemical AB, and contained less than $0.5 \%$ aromatics. 
An Orion (USA)720 ion analyser was used for the $\mathrm{pH}$ measurements. A Perkin Elmer Analyst 100 atomic absorption spectrophotometer (AAS) was used for metal ions determination in multi component mixtures.

Petroleum coke produced at the Syrian refineries was roasted with sodium carbonate, more than $60 \%$ of vanadium was recovered in multi stages with distilled water. The obtained leached solution was concentrated by evaporation and acidified by diluted sulfuric acid. Vanadium and the main impurity contents in the leached solution are represented in Table 1

Tab. 1. Components of vanadium leached solution

\begin{tabular}{cc}
\hline Concentration $(\mathrm{g} / \mathrm{l})$ & Element \\
\hline 0.3 & $\mathrm{~V}$ \\
0.487 & $\mathrm{Fe}$ \\
0.271 & $\mathrm{Al}$ \\
0.08 & $\mathrm{Ni}$ \\
\hline
\end{tabular}

Solvent extraction and stripping experiments were carried out by shaking required volumes of aqueous and organic phases in separatory funnels. Preliminary experiments showed that the extraction equilibria of vanadium (IV) in sulfuric acid solution with TBP/DEHPA in kerosene were attained within 3 to 4 min. Vanadium (IV) was analysed spectrophotometrically as Vanadium (V) after oxidation by nitric acid using hydrogen peroxide as a complex agent, Ryon et al. [12]. The content of the metal ion in the organic phase was then obtained by mass balance. The extraction distribution coefficient $\left(\mathrm{K}_{d}\right)$ is defined as:

$$
K_{d}=\frac{\text { metal ion concentration in organic phase }}{\text { metal ion concentration in aqueous phase }}
$$

The batch type counter current extraction and stripping experiments were performed using separatory funnels of suitable volumes.

\subsection{Extraction of vanadium (IV) with DEHPA.}

The extraction of vanadium in its tetravalent state from a weakly acidic solution by DEHPA (HA) may be represented by the following cation exchange reaction, Brunette et al. [7].

$\mathrm{nVO}^{2+}+\mathrm{m}(\mathrm{HA})_{2(\text { org })} \leftrightarrow(\mathrm{VO})_{n}(\mathrm{~A})_{2 n}(\mathrm{HA})_{2(m-n)(\text { org })}+2 \mathrm{n} \mathrm{H}^{+}$

It may be commented that at constant $\mathrm{pH}$ the distribution factor increases with the metal concentration at moderate loading of the organic phase. The dependence of extraction on $\mathrm{pH}$ and reagent concentration is positive as indicated by the given reaction, provided that a high extraction yield is obtainable in a multistage system. The importance of the kinetic conditions are involved and highlighted when competitive extraction of other metals is taking place. Tri-butyl phosphate (TBP) has been added to the organic phase as diluent modifier to improve phase separation characteristics. Chemical effects of TBP on extraction of vanadium (IV) in the present operation conditions are negative but small in magnitude. Moreover, DEHPA is an acidic extractant, forms a salt with vanadium, and TBP solvates this. The mechanism is thus similar to that of extraction by TBP alone. In most cases the effect is only observed at fairly low acidities, since otherwise the acidic extractant could not form a metal salt [14].

\section{Results and discussion}

DEHPA and TBP in amounts corresponding to a composition of $20 \%(\mathrm{v} / \mathrm{v})$ and $15 \%(\mathrm{v} / \mathrm{v})$ respectively in kerosene were prepared. Acidification of the loaded leached liquor characterized in Table 1 was carried out by diluted sulfuric acid. Liquors of $\mathrm{pH}$ : $0.5,1.0,1.5,2.0$ were prepared. Vanadium extraction tests showed that to obtain a significant extraction of vanadium $\mathrm{pH}$ value of the leached solution must be about 1.5 to 1.8 and it's oxidation potential between $250-300 \mathrm{mV}$ relative to a saturated calomel electrode. That is, most of the iron reduces to the ferrous condition and all vanadium to the tetravalent form to accomplish a separation between constituents in solvent extraction. Chemical analyses of $\mathrm{Fe}^{I I}$ and $\mathrm{Fe}^{I I I}$ in the aqueous solution indicate that ratio of $\mathrm{Fe}^{I I I} / \mathrm{Fe}^{I I}$ is $1 / 100$. It is well known that $\mathrm{Fe}^{I I I}$ is extracted by DEHPA and its distribution factor is higher than that of V(IV). However, the extraction kinetics of $\mathrm{Fe}^{I I I}$ is slow [3]. The extraction of $\mathrm{Fe}^{I I}$ is very low. Thus, provided the extraction kinetics for V(IV) is fast enough. A selective separation from iron in the leached solution with DEHPA might be possible.

\subsection{Extraction kinetics}

Tests were carried out using organic phase of DEHPA $(20 \%$ $\mathrm{v} / \mathrm{v})$ and TBP (15\%v/v) in kerosene and aqueous phase of $\mathrm{pH}$ $=1.5$. The parameters studied were the temperatures $(25,40$ and $\left.60^{\circ} \mathrm{C}\right)$ and the mixing time $(15,45,90,120,180,240,300$ and $600 \mathrm{sec}$ ). Organic and aqueous phases were mixed well to produce a homogenous mixture. A complete separation was carried out in a centrifuge at a predetermined temperature. The parameters studied were the initial $\mathrm{pH}$ value and the temperature. The simultaneous extraction of vanadium, iron and aluminum in terms of the extraction distribution coefficient as a function of time is represented in Tables 2, 3, and 4, The back extraction phenomenon is caused by the competitive extraction of iron and aluminum. The extraction of iron and aluminum will continuously acidify the aqueous phase and after some time the metal will significantly load the organic phase. These effects will adversely influence and subsequently decrease the vanadium extraction.

The higher the temperature the less time is available for vanadium to be extracted due to the fast extraction of iron and aluminum. This is obviously not compensated for by the increased distribution coefficient for vanadium, as the levels for the respective minima in Fig. 1 are higher for higher temperature. Thus, it is more advantageous from a chemical point of view to perform the extraction at a temperature in the interval between 25 and $40^{\circ} \mathrm{C}$. Furthermore, the extent of extraction of iron and alu- 
Tab. 2. Extraction of vanadium, iron and aluminum with $20 \%$ DEHPA $+15 \%$ TBP as a function of time at $25^{\circ} \mathrm{C}$. Initial feed $\mathrm{pH}$ is 1.5 .

Tab. 3. Extraction of vanadium, iron and aluminum with $20 \%$ DEHPA $+15 \%$ TBP as a function of time at $40^{\circ} \mathrm{C}$. Initial feed $\mathrm{pH}$ is 1.5 .

Tab. 4. Extraction of vanadium, iron and aluminum with $20 \%$ DEHPA $+15 \%$ TBP as a function of time at $60^{\circ} \mathrm{C}$. Initial feed $\mathrm{pH}$ is 1.5 .

\begin{tabular}{ccccccccc}
\hline Temp & $\begin{array}{c}\mathrm{pH} \\
25^{\circ} \mathrm{C}\end{array}$ & $\begin{array}{c}\text { Time } \\
(\mathrm{Sec})\end{array}$ & $\begin{array}{c}{[\mathrm{V}]_{\mathrm{org}}} \\
\mathrm{g} / \mathrm{l}\end{array}$ & $\begin{array}{c}\mathrm{K}_{d} \\
\mathrm{~V}\end{array}$ & $\begin{array}{c}{[\mathrm{Fe}]_{\text {org }}} \\
\mathrm{g} / \mathrm{l}\end{array}$ & $\begin{array}{c}\mathrm{K}_{d} \\
\mathrm{Fe}\end{array}$ & $\begin{array}{c}{[\mathrm{Al}]_{\text {org }}} \\
\mathrm{g} / \mathrm{l}\end{array}$ & $\begin{array}{c}\mathrm{K}_{d} \\
\mathrm{Al}\end{array}$ \\
\hline \multirow{2}{*}{ Feed } & & 1.5 & & 0.3 & & 0.487 & 0.271 \\
\hline & 1.48 & 15 & 0.037 & 0.2 & 0.004 & 0.01 & 0.002 & 0.007 \\
& 1.45 & 45 & 0.107 & 0.66 & 0.005 & 0.01 & 0.004 & 0.015 \\
& 1.44 & 90 & 0.154 & 1.39 & 0.008 & 0.017 & 0.01 & 0.038 \\
& 1.43 & 120 & 0.169 & 1.8 & 0.010 & 0.02 & 0.015 & 0.05 \\
& 1.43 & 180 & 0.198 & 2.75 & 0.0135 & 0.028 & 0.017 & 0.07 \\
& 1.42 & 240 & 0.207 & 3.5 & 0.015 & 0.03 & 0.019 & 0.075 \\
& 1.41 & 300 & 0.200 & 3.25 & 0.018 & 0.038 & 0.023 & 0.1 \\
& 1.37 & 600 & 0.191 & 2.7 & 0.027 & 0.06 & 0.036 & 0.15 \\
\hline
\end{tabular}

\begin{tabular}{ccccccccc}
\hline Temp & $\begin{array}{c}\mathrm{pH} \\
25^{\circ} \mathrm{C}\end{array}$ & $\begin{array}{c}\text { Time } \\
(\mathrm{Sec})\end{array}$ & $\begin{array}{c}{[\mathrm{V}]_{\text {org }}} \\
\mathrm{g} / \mathrm{l}\end{array}$ & $\begin{array}{c}\mathrm{K}_{d} \\
\mathrm{~V}\end{array}$ & $\begin{array}{c}{[\mathrm{Fe}]_{\text {org }}} \\
\mathrm{g} / \mathrm{l}\end{array}$ & $\begin{array}{c}\mathrm{K}_{d} \\
\mathrm{Fe}\end{array}$ & $\begin{array}{c}{[\mathrm{Al}]_{\text {org }}} \\
\mathrm{g} / \mathrm{l}\end{array}$ & $\begin{array}{c}\mathrm{K}_{d} \\
\mathrm{Al}\end{array}$ \\
\hline \multirow{2}{*}{ Feed } & \multicolumn{2}{c}{1.5} & & 0.3 & & 0.487 & 0.271 \\
\hline & 1.44 & 15 & 0.194 & 0.4 & 0.02 & 0.043 & 0.017 & 0.06 \\
& 1.39 & 45 & 0.192 & 1.06 & 0.040 & 0.09 & 0.034 & 0.129 \\
& 1.34 & 90 & 0.162 & 1.63 & 0.050 & 0.12 & 0.048 & 0.187 \\
& 1.33 & 120 & 0.155 & 1.76 & 0.054 & 0.126 & 0.059 & 0.234 \\
& 1.33 & 180 & 0.128 & 1.25 & 0.060 & 0.140 & 0.076 & 0.31 \\
& 1.29 & 240 & 0.11 & 1.10 & 0.062 & 0.146 & 0.086 & - \\
& 1.27 & 300 & 0.10 & 0.7 & 0.063 & 0.149 & 0.094 & - \\
& 1.23 & 600 & 0.085 & 0.5 & 0.067 & 0.160 & 0.11 & 0.47 \\
\hline
\end{tabular}

\begin{tabular}{|c|c|c|c|c|c|c|c|c|}
\hline Temp & $\begin{array}{c}\mathrm{pH} \\
25^{\circ} \mathrm{C}\end{array}$ & $\begin{array}{l}\text { Time } \\
\text { (Sec) }\end{array}$ & $\begin{array}{c}{[\mathrm{V}]_{\text {org }}} \\
\mathrm{g} / \mathrm{l}\end{array}$ & $\begin{array}{c}\mathrm{K}_{d} \\
\mathrm{~V}\end{array}$ & $\begin{array}{c}{[\mathrm{Fe}]_{\text {org }}} \\
\mathrm{g} / \mathrm{l}\end{array}$ & $\begin{array}{l}\mathrm{K}_{d} \\
\mathrm{Fe}\end{array}$ & $\begin{array}{c}{[\mathrm{Al}]_{\text {org }}} \\
\mathrm{g} / \mathrm{l}\end{array}$ & $\begin{array}{r}\mathrm{K}_{d} \\
\mathrm{Al}\end{array}$ \\
\hline Feed & \multicolumn{2}{|c|}{1.5} & \multicolumn{2}{|c|}{0.3} & \multicolumn{2}{|c|}{0.487} & \multicolumn{2}{|c|}{0.271} \\
\hline \multirow{8}{*}{$60^{\circ} \mathrm{C}$} & 1.33 & 15 & 0.190 & 2.0 & 0.026 & 40.05 & 0.016 & 0.06 \\
\hline & 1.23 & 45 & 0.220 & 2.3 & 0.041 & 0.09 & 0.036 & 0.152 \\
\hline & 1.19 & 90 & 0.160 & 1.08 & 0.051 & 0.12 & 0.082 & 0.43 \\
\hline & 1.16 & 120 & 0.154 & 0.98 & 0.058 & 0.14 & 0.134 & 0.97 \\
\hline & 1.13 & 180 & 0.125 & 0.71 & 0.062 & 0.15 & 0.142 & 1.27 \\
\hline & 1.11 & 240 & 0.110 & 0.52 & 0.063 & 0.152 & 0.149 & 1.42 \\
\hline & 1.11 & 300 & 0.101 & 0.48 & 0.065 & 0.157 & 0.162 & 1.62 \\
\hline & 1.08 & 600 & 0.088 & 0.4 & 0.068 & 0.163 & 0.174 & 1.92 \\
\hline
\end{tabular}


minum will be much less in the given interval, as is shown by the kinetic data in Tables 2, 3 and 4. It is essential to keep the contact time as low as possible in order to minimize the extraction of iron and aluminum.
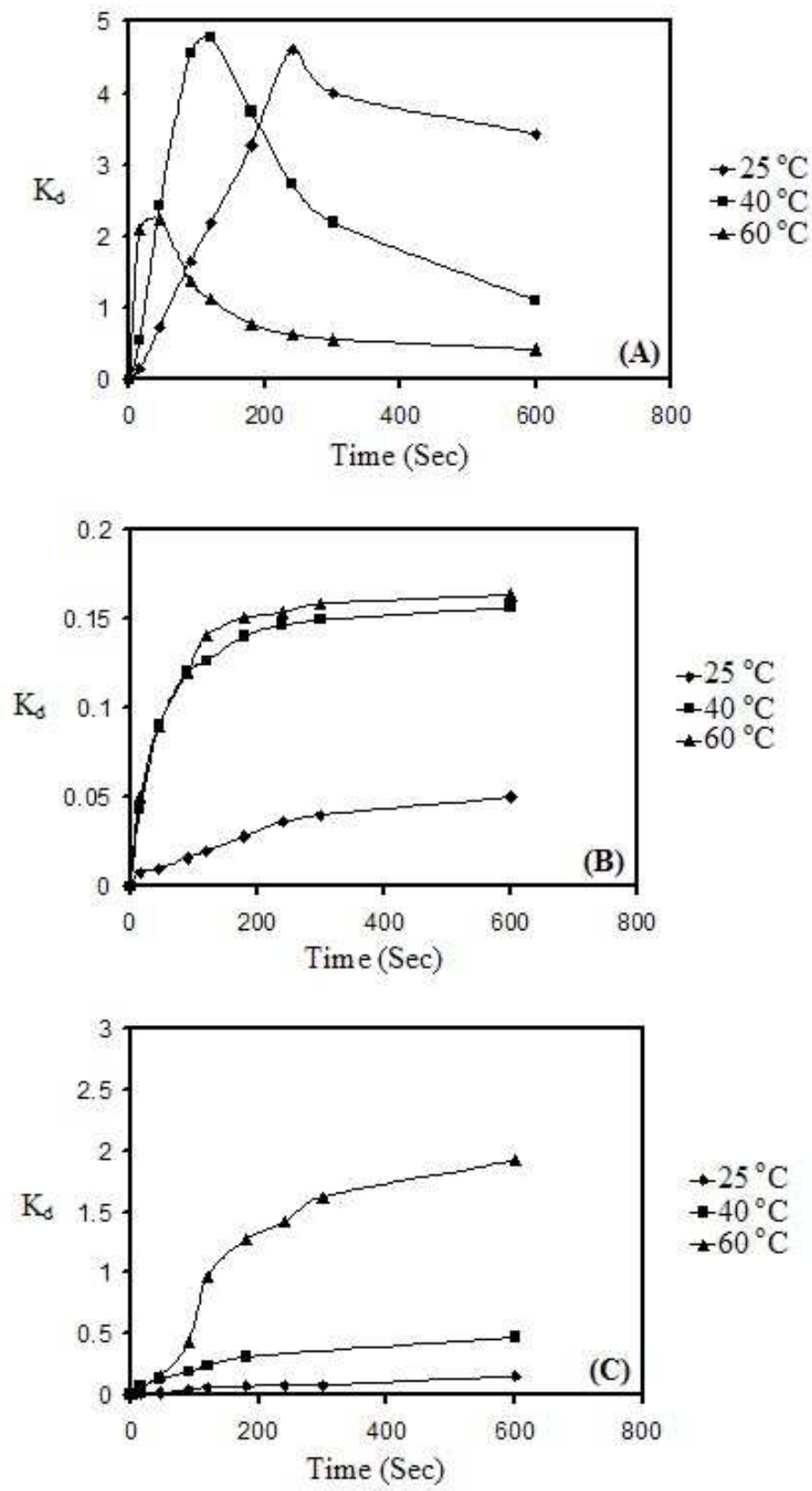

Fig. 1. Vanadium, iron and aluminum distribution coefficients $\left(\mathrm{K}_{d}\right)$ as a function of time, $\mathrm{A}, \mathrm{B}$ and $\mathrm{C}$ respectively

\subsection{Solvent Extraction}

Equilibrium data at $25^{\circ} \mathrm{C}$ for the extraction of vanadium from a representative feed solution with 20\% DEHPA and 15\% TBP is presented in Fig. 2, different phase ratios of organic/aqueous have been mixed at $25{ }^{\circ} \mathrm{C}$ for 4 minutes. Vanadium was determined in both phases after phase separation by a centrifuge. The MacCabe-Thiel construction indicates a yield of approximately $80 \%$ with three theoretical stages at a flow ratio of 3:1 (organic to aqueous) with a residence time of about 4 minutes.
Vanadium is stripped under moderate acid conditions with $1.5 \mathrm{M} \mathrm{H}_{2} \mathrm{SO}_{4}$. The kinetic conditions at $25{ }^{\circ} \mathrm{C}$ are such that equilibrium is reached in 10 to 15 minutes in batch experiment. Somewhat longer residence time is therefore needed than the extraction section. The kinetic for iron stripping is slower compared to vanadium. To insure sufficient stripping capacity to prevent accumulation of iron in the organic phase, a high residence time will be used. The stripping yield increases with acid concentration, which will be about $6 \mathrm{M}$.

Stripping of vanadium and iron to the same solution according to figure 3 is being tested. Where, most of vanadium is stripped with a solution made by dilution of the strong acid solution from the following stage for stripping of iron. The organic solution is then washed with water to recover extracted and entrained $\mathrm{H}_{2} \mathrm{SO}_{4}$.

Precipitation of vanadium in its tetravalent state from the pregnant strip solution at a $\mathrm{pH}$ of 10 to 12 with ammonia was carried out. Iron will also precipitate under these conditions. Table 5 shows the ammonia precipitate vanadium composition after through washing and drying. Precipitation with sodium carbonate is not favourable with too high sulfate content. Where, ammonia sulfate may be eliminated by calcination and will yield a rather pure product (less iron impurity).

Tab. 5. Composition of vanadium precipitate

\begin{tabular}{cc}
\hline Composition & $\%$ \\
\hline $\mathrm{V}$ & 52.7 \\
$\mathrm{Fe}$ & 0.08 \\
$\mathrm{Ni}$ & 0.07 \\
$\mathrm{~S}$ & 0.09 \\
$\mathrm{SiO}_{2}$ & 0.02 \\
\hline
\end{tabular}

\section{Conclusion}

Using DEHPA/TBP in kerosene composition as a solvent for vanadium extraction from acid sulfate media the following should be considered:

- Vanadium should be tetravalent.

- Iron must be reduced to its bivalent state before the extraction stages to minimize its extraction.

- The temperature of the extraction stage may be between 25 and $40^{\circ} \mathrm{C}$ however, too high temperature is negative because of excessive iron extraction.

- A closed process cycle has been proposed for partial extraction of vanadium. 
Fig. 2. MacCabe-Thiel diagram for extraction of vanadium with $20 \%$ DEHPA $+15 \%$ TBP

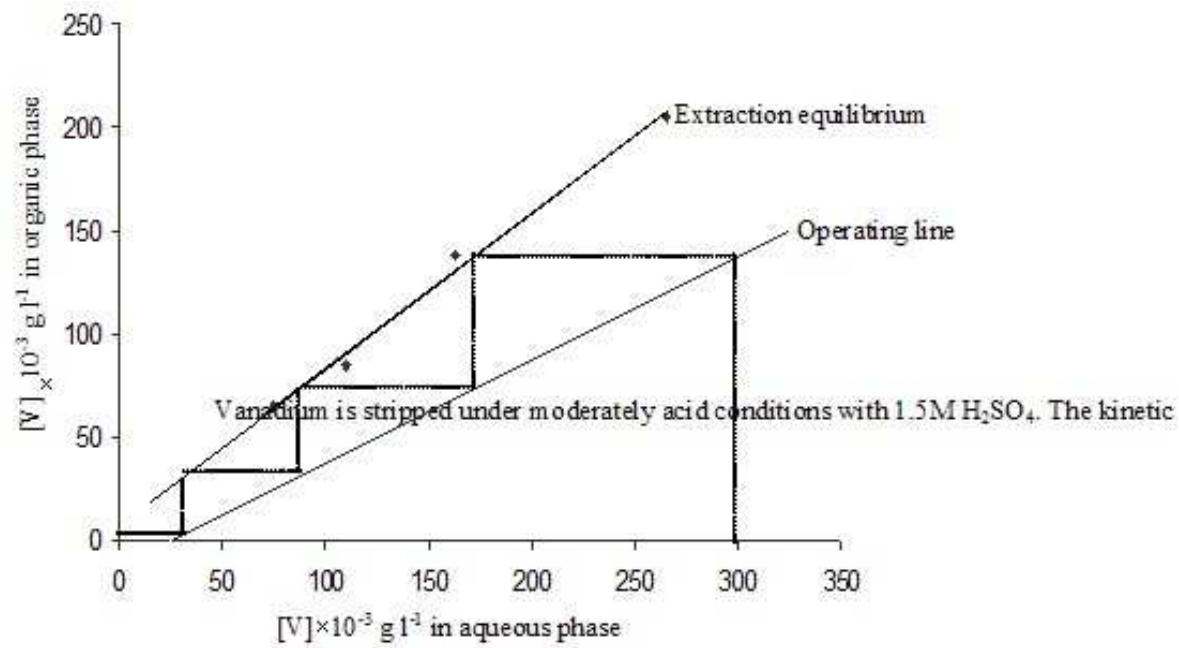

Fig. 3. Flow sheet of vanadium extract and stripping of vanadium and iron.

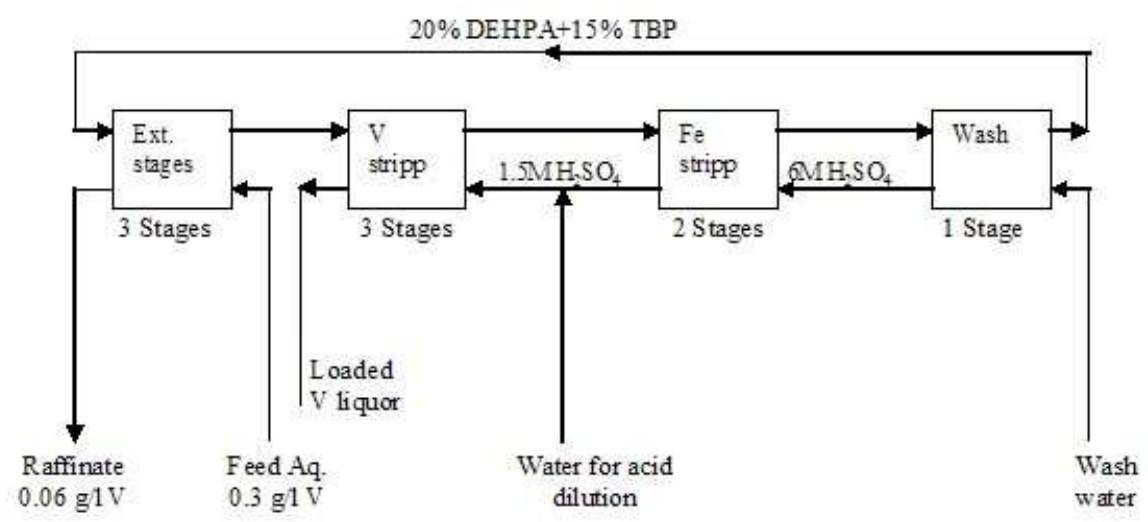

\section{References}

1 Toyabe KT, Kirishima KK, Shibayama HT, Hanawa HK, Process for Recovering Valuable Metal from Waste Catalyst, July 11 1995. US patent 5, 431, 892.

2 Gupta CK, Extraction metallurgy of niobium, tantalum and Vanadium, International Metals Reviews 29 (1984), 405-444.

3 Gupta CK, Krishnamurthy N, Extractive Metallurgy of Vanadium, Elsevier, 1992.

4 Remya PN, Saji J, Reddy ML, Solvent extraction and separation of vanadium (V) from multivalent metal chloride solutions by Cyanix 923, Solvent extraction and ion exchange 21 (2003), no. 4, 573-589.

5 Biswas RK, Wakihara M, Taniguchi M, Recovery of Vanadium and molybdenum from heavy oil desulphurisation waste catalyst, Hydrometallurgy $\mathbf{1 4}$ (1985), 219-230.

6 Hirai T, Hashimoto T, Tsuboi I, Hino A, Komasawa I, Extraction and separation of molybdenum and vanadium using Bis(2- ethylhexyl) monothiophosphoric acid and Bis(2-ethylhexyl) phosphoric acid, J. Chem. Eng. Japan 28 (1995), 85-90.

7 Brunette JP, Rastegar F, Leroy MJF, Solvent Extraction of Vanadium (V) by Di-(2-ethylhexyl) phosphoric acid from nitric acid solutions, J. Inorg. Nucl. Chem. 41 (1979), 735-737.

8 Zhang P, Inoue K, Yoshizuka K, Tsuyama H, Solvent Extraction of Vanadium (IV) from sulfuric acid solutions by Bis (2,4,4-Trimethylpentyl) phosphinic acid in EXXSOL D80., J. Chem. Eng. Japan 29 (1996), 82-87.

9 Saji J, Reddy MLP, Solvent Extraction separation of vanadium (V) from multivalent metal chloride solutions by 2- ethylhexyl phosphonic acid mono2-ethylhexyl ester., J. Chem. Technol. Biotech. 77 (2002), 1149-1256.

10 Tedesco PH, De Rumi VB, Vanadium (V) Extraction by tri-butylphosphate from hydrochloric acid solutions, J. Inorg. Nucl. Chem. 42 (1978), 269-272.

11 Crouse DJ, Brown KB, USAEC, ORNL 2820, Nov. 1959.
12 Ryon AD, Daley FL, Lowrie RS, USAEC, ORNL-2951, Oct. 1960.

13 Mirritt R C, The extractive Metallurgy of Uranium., Colorado School of Mines Research Institute, 1971.

14 Schulz WW, Navratil JD, Science and Technology of TBP, Vol. 1, CRC press, 1984. 